\title{
A!
}

This is an electronic reprint of the original article.

This reprint may differ from the original in pagination and typographic detail.

Wang, Ping; Li, Hongxiu; Liu, Yong

Disentangling the factors driving electronic word-of-mouth use through a configurational approach

Published in:

INTERNET RESEARCH

DOI:

10.1108/INTR-01-2019-0031

Published: 01/02/2020

Document Version

Peer reviewed version

Please cite the original version:

Wang, P., Li, H., \& Liu, Y. (2020). Disentangling the factors driving electronic word-of-mouth use through a configurational approach. INTERNET RESEARCH, 30(3), 925-943. https://doi.org/10.1108/INTR-01-2019-0031

This material is protected by copyright and other intellectual property rights, and duplication or sale of all or part of any of the repository collections is not permitted, except that material may be duplicated by you for your research use or educational purposes in electronic or print form. You must obtain permission for any other use. Electronic or print copies may not be offered, whether for sale or otherwise to anyone who is not an authorised user. 


\section{Disentangling the Factors Driving Electronic Word-of-Mouth Use through a Configurational Approach}

Purpose: The purpose of this paper is to show how different combinations of the sub-dimensions of electronic word-of-mouth (eWOM) information quality (consisting of its accuracy, completeness, relevance, timeliness, and sidedness) may affect consumers' eWOM use behavior from a configurational approach.

Design/methodology/approach: Based on a synthesis of past literature, five precursors of eWOM use were considered. A fuzzy-set qualitative comparative analysis (fsQCA) was employed to understand configurations that lead to travel-related eWOM use. The study was conducted with 311 consumers from an online travel service company.

Findings: Findings identified six solutions that explain eWOM use. EWOM accuracy, completeness, and sidedness are found to be core conditions reinforcing consumers' use of eWOM in combination with different peripheral conditions, including the sub-dimensions of eWOM information quality and the traits of the consumers (such as social media use time and gender).

Practical implications: Factors related to eWOM information quality and traits of the consumers, when considered in combination, predict eWOM use behavior in particular sets of conditions.

Originality/value: This work enriches the eWOM literature by providing an in-depth understanding of eWOM use from a configuration perspective. Configuration analysis serves as a better tool for explaining the complex relationships among variables than a regression analysis approach does. Additionally, in response to the need to move beyond multiple regression analysis to algorithmic approaches, this study shifts the emphasis from a symmetric paradigm to an asymmetric perspective for data analysis focused on eWOM use.

Keywords: eWOM use, fuzzy-set qualitative comparative analysis, fsQCA, configuration analysis

\section{Introduction}

Electronic word of mouth (eWOM) has been recognized as an influential marketing channel in business. Compared to reviews created as marketing or editorial efforts, consumer-generated eWOM is perceived as highly trustworthy on account of a sense that it possesses high levels of integrity (Dickinger, 2011). Consumers rely heavily on eWOM to reduce their search efforts prior to purchase (Bronner and De Hoog, 2011), to decrease risks in their purchasing (Kim et al., 2011), and to support their purchase decisions (Serra Cantallops and Salvi, 2014). Therefore, deciphering the factors behind consumers' use of eWOM in their purchase-related decision-making has attracted considerable attention among researchers in different fields.

eWOM information quality has been identified as one of the main factors influencing consumers' eWOM use as well as their purchase decision-making (Hussain et al., 2018; Kim et al., 2017). Information quality of eWOM is a composite construct with sub-dimensions, such as information accuracy, relevance, completeness, sidedness, valance, understandability, and timeliness (Cheung et al., 2008; Filieri and McLeay, 2014). The dimensions of information quality have been found to affect users' perceptions about the usefulness of eWOM and their use of eWOM (Hussain et al., 2018; Kim et al., 2017). 
Extant research exploring the relationship between eWOM information quality and eWOM use have mainly employed statistical techniques. Structural equation modeling (SEM) and multiple regression analysis (MRA) are the most frequent methods employed in examining the link between driving factors for consumers' eWOM use. Regression analysis is conducted based on an assumption of symmetric relationships between the independent and dependent variables, and it focuses on the net effect (Woodside, 2013). For example, high values of the independent variable $X$ (here, subdimension of eWOM quality) are both necessary and sufficient for high values of the dependent variable $Y$ (eWOM use), and vice versa. However, some scholars have argued that eWOM information quality might exert an asymmetric effect on consumers' perceptions of eWOM usefulness and their eWOM use, and call for further research in this field (Park and Nicolau, 2015).

Fuzzy-set qualitative comparative analysis (fsQCA) is a configurational approach that has been applied in exploring asymmetric relationships. The configurational approach opens new paths to understanding asymmetric relationships between variables. It has been argued to be essential in obtaining a deep understanding of real-life phenomena (Kraus et al., 2018; Ragin, 2009; Woodside, 2013). Configuration analysis, including fsQCA, has already been used to explain user behavior in the information systems (IS) field, and fsQCA has been recommended as an alternative approach for such work (Liu et al., 2017). For instance, in recent years, fsQCA has attracted the attention of scholars in business and management research, specifically with regard to use of personalized services in the e-commerce domain (Pappas et al., 2016), IS behavioral research (Liu et al., 2017), consumers' satisfaction with online information (Kourouthanassis et al., 2017), and social media user behavior ( $\mathrm{Li}$ et al., 2018). Thus, the fsQCA method is employed in this study for its value in exploring the asymmetric nonlinear relationships between eWOM information quality and eWOM use.

This study contributes to the eWOM literature by adding fsQCA to the toolbox of methods for entangling how different sub-dimensions of information quality of eWOM and user traits interact to facilitate eWOM use. With this alternative to the traditional statistical methods, our work is, to the best of our knowledge, the first attempt to use configuration analysis to explain eWOM use behavior, thereby taking advantage of the configuration perspective to enrich the understanding of eWOM use from that yielded by regression analysis.

The discussion below proceeds as follows: A literature review is provided on eWOM use in section two, after which we describe the methodology applied in our study in section three. Section four presents the data analysis, after which we offer discussion of the findings and the conclusions that emerged. The limitations of this study and suggestions for future research are considered at the end of the article.

\section{Literature review}

\subsection{Research on eWOM}

eWOM has been a popular research topic in different research fields, such as IS and marketing. Diverse SEM-based theories have been employed to explain eWOM use, such as the elaboration likelihood model (Filieri and McLeay, 2014), the heuristic-systematic model (Zhang et al., 2014), cognitive fit theory (Park and Kim, 2008), social presence theory (Xu, 2014), and source credibility theory (Reichelt et al., 2014). As social communication, eWOM communication has been identified as having four major elements - namely, the communicators (a source), the stimulus (content), the receiver (an audience), and the response (the main effect, such as attitudes toward eWOM use, eWOM use, purchasing intention, and purchase) (Cheung and Thadani, 2012). Most studies of eWOM have investigated the phenomenon primarily in terms of these elements of social communication. 
Within this broad outline, there are three main streams of research into eWOM use behavior. The first is focused principally on the predictors of eWOM use from the eWOM content perspective. Content quality has been suggested to be a salient factor in consumers' use of eWOM in purchasing-decision support (Sparks et al., 2013). The eWOM information quality has been considered a composite construct in most studies, although that approach fails to address the importance of the individual dimensions of information quality in predicating eWOM use among consumers. Some scholars have recently conceptualized the quality of eWOM content as a synthesis of several sub-dimensions. For instance, Cheung et al. (2008) measured eWOM content quality along four subsidiary dimensions: eWOM completeness, timeliness, accuracy, and relevance. Filieri and McLeay (2014), in turn, measured all of these and also the understandability and added-value aspects of eWOM content. In addition, attributes of information content such as its sidedness, writing style, review length, and rating have been suggested to be important factors connected with eWOM content quality that influence consumers' trust in the eWOM, its perceived helpfulness, and, ultimately, eWOM use (Mudambi and Schuff, 2010). Some research has demonstrated that discrete emotions expressed in the eWOM, such as hope, happiness, anxiety, and disgust, influence consumers' eWOM use (Ahmad and Laroche, 2015).

The second body of work consists of attempts to examine eWOM use from the communicator perspective - that is, with regard to the reviewer who generates the eWOM. The literature has identified several reviewer-related elements as determining factors in consumers' attitudes toward eWOM and in their extent of eWOM use. Among these are expertise, information provided in the reviewer's online profile, and reputation. Reviewers' credibility, thus influenced, operates alongside eWOM information quality (expressed in eWOM rating, etc.) to shape consumers' eWOM evaluation and use (Baek et al., 2012). Cheung et al. (2012) have argued that consumers trust reviewers who have a favorable reputation (stemming from aspects of review behavior such as the average product rating in a specific category) and intend to use eWOM from them. Exploring more features linked to reviewers, Hu et al. (2016) found that reviewers' gender, experience in the relevant online venue, and contribution to eWOM forums determine consumers' perception of the helpfulness of reviewers, which will lead to eWOM use.

Researchers taking the third approach to eWOM use have argued that features related to the receivers of eWOM - the consumers - affect their perceptions of the trustworthiness or helpfulness of eWOM and their eWOM use. Consumers' social media use experience has also been demonstrated to affect the trust in eWOM, which is vital in determining consumers' intention to heed eWOM (Filieri, 2016; Filieri et al., 2015). Matook et al. (2015) found that online experience with social networks and posting eWOM exert a positive influence on consumers' intention to use eWOM, such as to make a purchase based on recommendations in eWOM. Abubakar et al. (2017) found that men trust eWOM more than women, and the impact of eWOM on the intention to visit travel destinations among women is higher than among men.

Prior literature provides a deep understanding of eWOM use considering the importance of eWOM information quality and characteristics of its consumers. Proceeding from the definition of information quality applied in IS research and taking the specific characteristics of eWOM into account, we developed five constructs closely related to eWOM information quality to capture the information quality for purposes of our study: information accuracy (IA), information completeness (IC), information timeliness (IT), information relevance (IR), and information sidedness (IS). Gender is considered in our exploration of eWOM use configurations in order to explore different configurations among different consumer groups (such as female and male consumers). Social media usage has been found to influence consumers' online information search behavior, such as in 
consumers' searching of eWOM (Luo and Zhong, 2015). Thus, consumers' social media use time is also taken into consideration in our research model.

\subsection{Fuzzy-set qualitative comparative analysis}

FsQCA, developed by the social scientist Ragin (2014), follows configuration theory and examines the interplay among elements of a messy and non-linear nature that form configurations in realizing the outcome of interest (Fiss, 2011). fsQCA is a set-theoretic analysis approach, which is based on the assumption of causal complexity between conditions and an outcome which is asymmetric and nonlinear (Ragin, 2008). Unlike most quantitative methods, which are based on correlation, fsQCA seeks to establish logical connections of combinations of causal conditions with the outcome (Mendel and Korjani, 2012). In fsQCA methodology, a case is described as a combination of "causal conditions," and the determinants of an outcome of interest are combinations of distinct causal conditions (configurations) (Ragin, 2000). The fsQCA approach differs greatly from regressionbased analysis. Regression-based analysis relies on the principles of additive effects, linearity, and 'unifinality', and is concerned with the net impact of a single independent variable on the outcome of interest (Ragin, 2000, 2008; Woodside, 2013). In contrast, fsQCA can elicit various configurations that are sufficient for leading to the outcome in question. Consequently, the set-based fsQCA approach offers an appropriate means for exploring the complex interplay and non-linear relations among multiple variables (e.g., sub-dimensions of eWOM information quality and consumer traits) that will jointly lead to the outcome of interest (here, eWOM use behavior). In other words, numerous variables can work together to bring about the outcome of interest, and, further, several "recipes" may exist for combining multiple variables; these are "configurations" (Liu et al., 2017). FsQCA was primarily developed for small sample sizes, for example between ten and fifty cases, and has also been applied with medium- and large-sized datasets (Cooper and Glaesser, 2011; Kent, 2005).

In the past few years, the application of the fsQCA method has increased in various research fields, including organization management (Mikalef and Pateli, 2017), politics (Pérez Durán and Rodríguez Menés, 2017), social science (Tho, 2018), IS behavior (Li et al., 2018; Liu et al., 2017; Pappas et al., 2017), innovation research (Bacon et al., 2019; To et al., 2019), and hospitality management (Pappas, 2018, 2019). For instance, Kraus et al. (2018) reviewed 77 journal articles in business and management research applying the fsQCA method and suggested that fsQCA is an accepted and growing analysis method that shapes thinking and crafts theory, given its capability to capture the complexity of causally relevant conditions. A brief summary of recent research applying fsQCA in different research fields is presented below in Table 1.

Configuration theories can address the possibility of multiple combinations of conditions leading to a given outcome, such as eWOM use in this study. Woodside (2013) also posited that fsQCA is useful for examining asymmetric relations among variables and for illustrating the presence and absence of causal conditions necessary for the outcome of interest to be actualized. Based on this background, in this study we selected fsQCA as the data-analysis technique to explore the configurations with which the outcome of eWOM use emerges. Specifically, we attempted to scrutinize the asymmetric relationships between multiple dimensions of perceived eWOM information quality (information accuracy, information completeness, information timeliness, information relevance, and information sidedness) and eWOM use behavior among different user groups (such as female and male groups, and users with different social media use time) and to gain a deep understanding of the configurations of eWOM use behavior. 
Table 1. Recent research applying fsQCA

\begin{tabular}{|l|l|l|}
\hline \multicolumn{1}{|c|}{ Authors } & \multicolumn{1}{|c|}{ Research context } & \multicolumn{1}{c|}{ Data type } \\
\hline Beynon et al. (2019) & $\begin{array}{l}\text { Business (entrepreneurship, innovation, } \\
\text { and geography on state-level growth) }\end{array}$ & Secondary data \\
\hline Bacon et al. (2019) & $\begin{array}{l}\text { IS behavior (knowledge transfer in open } \\
\text { innovation ecosystems) }\end{array}$ & Semi-structured interview data \\
\hline Li et al. (2018) & $\begin{array}{l}\text { IS behavior (social media continuance } \\
\text { intention) }\end{array}$ & Survey data (N =297) \\
\hline Liu et al. (2017) & $\begin{array}{l}\text { IS behavior (mobile government services } \\
\text { adoption) }\end{array}$ & Survey data (N=409) \\
\hline Mikalef and Pateli (2017) & $\begin{array}{l}\text { Business (the effect of IT on competitive } \\
\text { performance) }\end{array}$ & Survey data (N=274) \\
\hline $\begin{array}{l}\text { Ortiz de Guinea and } \\
\text { Raymond (2020) }\end{array}$ & IT management (IT ambidexterity) & Secondary data (N=63) \\
\hline Pappas (2018) & Tourism & Survey data (N=243) \\
\hline Pappas (2019) & Tourism (consumer experience) & Survey data (N =712) \\
\hline $\begin{array}{l}\text { Pappas } \text { et al. (2019) } \\
\text { Business and IS (mobile gaming } \\
\text { application download intention) }\end{array}$ & Survey data (N=531) \\
\hline $\begin{array}{l}\text { Pérez Durán and Rodríguez } \\
\text { Menés (2017) }\end{array}$ & Politics (health policy in Spain) & Secondary data \\
\hline To et al. (2019) & Business (business model innovation) & Survey data (N =42) \\
\hline Tho (2018) & Social science (human capital resource) & Survey data (N =396) \\
\hline $\begin{array}{l}\text { Vizcaino-Gonzalez et al. } \\
\text { (2017) }\end{array}$ & Social science (voting decision) & $\begin{array}{l}\text { Secondary data (voting data } \\
\text { disclosed from 2003-2013) }\end{array}$ \\
\hline
\end{tabular}

\section{Methodology}

\subsection{Development of the measurement approach}

Based on the proposed research model, six constructs were selected for exploring eWOM use behavior: information accuracy, information completeness, information relevance, information sidedness, information timeliness, and eWOM use. The items for each construct were revised in line with previously validated scales, for fitting to the research context and for greater reliability and validity of the measurements. Our questionnaire was developed in English and then translated into Chinese, after which, for consistency of the questionnaire content between the English and the Chinese version, the Chinese-language version was translated back into English. We conducted a pilot study among 20 users with experience of using travel-review (eWOM) platforms and creating travel reviews to test the questionnaire. This study used a seven-point Likert scale ranging from 1 ("strongly disagree") to 7 ("strongly agree") to measure the items for all constructs. The details of the constructs are presented in Table 2. 
Table 2. The survey constructs and questions

\begin{tabular}{|c|c|}
\hline Constructs & Items \\
\hline $\begin{array}{l}\text { Information accuracy } \\
\text { (IA) } \\
\text { (Cheung et al., 2008) }\end{array}$ & $\begin{array}{l}\text { The eWOM provided the correct information for my travel plans. } \\
\text { There were few errors in the information I obtained from the eWOM. } \\
\text { The information from the eWOM tends to be accurate. }\end{array}$ \\
\hline $\begin{array}{l}\text { Information } \\
\text { completeness } \\
\text { (IC) } \\
\text { (Cheung et al., 2008) }\end{array}$ & $\begin{array}{l}\text { The eWOM provided me with complete information for my travel. } \\
\text { The eWOM provided me with comprehensive information for my travel. } \\
\text { The eWOM provided me with all the information I needed for my travel. }\end{array}$ \\
\hline $\begin{array}{l}\text { Information Timeliness } \\
\text { (IT) } \\
\text { (Cheung et al., 2008) }\end{array}$ & $\begin{array}{l}\text { The eWOM provided me with the most up-to-date information for my travel- } \\
\text { related decision. } \\
\text { The eWOM produced the most current information for my travel-related } \\
\text { decision. } \\
\text { The eWOM from the travel review sites is always up-to-date. }\end{array}$ \\
\hline $\begin{array}{l}\text { Information relevance } \\
\text { (IR) } \\
\text { (Cheung et al., 2008) }\end{array}$ & $\begin{array}{l}\text { The eWOM on the travel-review website was relevant for my travel plans. } \\
\text { The eWOM on the travel-review website was appropriate for my travel } \\
\text { plans. } \\
\text { The eWOM on the travel-review website was applicable to my travel } \\
\text { decision-making. }\end{array}$ \\
\hline $\begin{array}{l}\text { Information sidedness } \\
\text { (IS) } \\
\text { (Cheung et al., 2012) }\end{array}$ & $\begin{array}{l}\text { The eWOM included both the pros and the cons of the product/service } \\
\text { discussed. } \\
\text { The eWOM included both positive and negative comments. }\end{array}$ \\
\hline $\begin{array}{l}\text { eWOM use } \\
\text { (USE) } \\
\text { (Sussman and Siegal, } \\
\text { 2003) }\end{array}$ & $\begin{array}{l}\text { I used eWOM on the website for travel-related decision-making. } \\
\text { The eWOM provided on the website motivated me to take action/make a } \\
\text { reservation. } \\
\text { I agree with the eWOM provided on the website. }\end{array}$ \\
\hline
\end{tabular}

\subsection{Collection of the data}

The empirical data-collection work was conducted online with the aid of an online travel-service company in China. The survey invitations including a link to the questionnaire were distributed to the consumers (social media followers of the online travel-service company) via its official social media account on the WeChat platform. The respondents of interest were those who had recently used travel-review platforms and utilized eWOM for travel-related decision-making. To encourage participation, respondents who took part in the survey could be entered in a raffle for a prize. In the two-week data-collection window, a total of 351 responses were received. After screening the data, 40 respondents were excluded for having given inconsistent answers or not having had experience using travel-review websites. Therefore, there were 311 valid response sets. As shown in Table 3, most of the respondents are younger than 50 years old. According to a report on online tourism development in China in 2018, the online tourism consumers in China mainly consist of people born between 70 s to 2000 s, consisting $73.18 \%$ of the whole online travel customers in China (Travel Daily, 2018). And 26.82\% of online tourism consumers are above 50 years old (Travel Daily, 2018). In our data set, most of the respondents are between 18-50 years old, indicating that the sample in this study presents the premier groups of online tourism consumers in China market. In the sample, most of the respondents (60.1\%) are female. According to a recent report on gender distribution among Chinese online tourism consumers, female travelers takes about $60 \%$ of Chinese online tourism consumers and the travel decisions are more likely to be made by females (Tour.youth.cn, 2019). Thus, the sample in this study can be appropriate to investigate Chinese online tourism consumers. Details of the demographic characteristics of the 311 respondents considered are presented in Table 3. 
Table 3. Demographic characteristics of the respondents

\begin{tabular}{|c|c|c|c|}
\hline \multicolumn{2}{|c|}{ Demographic characteristics } & Occurrences in the data & Percentage $(\%)$ \\
\hline \multirow[t]{2}{*}{ Gender } & Male & 124 & 39.9 \\
\hline & Female & 187 & 60.1 \\
\hline \multirow[t]{5}{*}{ Age (years) } & $18-25$ & 96 & 30.9 \\
\hline & $26-30$ & 109 & 35.0 \\
\hline & $31-40$ & 80 & 25.7 \\
\hline & $41-50$ & 23 & 7.4 \\
\hline & $\geq 51$ & 3 & 1.0 \\
\hline \multirow{4}{*}{$\begin{array}{l}\text { Social media use } \\
\text { time } \\
\text { (hours/week) }\end{array}$} & Under 5 & 88 & 28.3 \\
\hline & $5-10$ & 94 & 30.2 \\
\hline & $11-20$ & 61 & 19.6 \\
\hline & More than 20 & 68 & 21.9 \\
\hline \multirow{4}{*}{$\begin{array}{ll}\text { Preferred } & \text { trip } \\
\text { style }\end{array}$} & Self-organized & 212 & 68.2 \\
\hline & Group travel & 16 & 5.1 \\
\hline & $\begin{array}{l}\text { Customized } \\
\text { travel }\end{array}$ & 80 & 25.7 \\
\hline & Other & 3 & 1.0 \\
\hline \multirow{6}{*}{$\begin{array}{l}\text { Leisure travel in } \\
\text { the previous } \\
\text { calendar year } \\
\text { (number of } \\
\text { trips) }\end{array}$} & 0 & 9 & 2.9 \\
\hline & 1 & 47 & 15.1 \\
\hline & 2 & 112 & 36.0 \\
\hline & 3 & 60 & 19.3 \\
\hline & 4 & 25 & 8.0 \\
\hline & 5 & 58 & 18.6 \\
\hline
\end{tabular}

\subsection{Measurement reliability and validity}

To evaluate the variables for convergent validity and reliability of the survey instrument, factor loadings for every item, composite reliability (CR), and the average variance extracted (AVE) were calculated for each construct. The results of this testing, presented in Table 4, indicate factor loadings exceeding 0.80 for all items, and the AVE and CR values comply with the recommended thresholds $(0.5$ and 0.8 , respectively). As the table shows, the Cronbach's alpha values for all constructs are between 0.846 and 0.908 , well above the 0.7 threshold. Hence, the tests confirmed the reliability of the proposed research and attest to the study's convergent validity (Bagozzi et al., 1981; Hair et al., 2013).

We calculated discriminant validity by calculating the square root of AVE for all the constructs used in the study. As can be seen in Table 5, the square root of AVE for each construct is greater than its correlation with other constructs, suggesting adequate discriminant validity for all the measurements (Bagozzi et al., 1981). Table 6 depicts the cross-loading test results for discriminant validity. Additionally, the heterotrait-monotrait (HTMT) ratio of the correlations was calculated to assess the discriminant validity in our variance-based SEM model (Henseler et al., 2015). As shown in Table 7, the highest HTMT ratio is 0.877 , meeting the HTMT.90 criteria, and all other HTMT ratios are below the most conservative criterion, HTMT.85, which indicates that the discriminant validity has been established in our model (Henseler et al., 2015). 
Table 4. Construct reliability and validity

\begin{tabular}{|c|c|c|c|c|c|}
\hline Constructs & Items & Factor loadings & $\mathrm{CR}$ & Cronbach's alpha & AVE \\
\hline \multirow{3}{*}{$\begin{array}{l}\text { Information } \\
\text { accuracy } \\
\text { (IA) }\end{array}$} & IA1 & 0.836 & \multirow{3}{*}{0.907} & \multirow{3}{*}{0.847} & \multirow{3}{*}{0.767} \\
\hline & IA2 & 0.880 & & & \\
\hline & IA3 & 0.908 & & & \\
\hline \multirow{3}{*}{$\begin{array}{l}\text { Information } \\
\text { completeness } \\
\text { (IC) }\end{array}$} & IC1 & 0.896 & \multirow{3}{*}{0.917} & \multirow{3}{*}{0.864} & \multirow{3}{*}{0.786} \\
\hline & $\mathrm{IC} 2$ & 0.914 & & & \\
\hline & IC3 & 0.848 & & & \\
\hline \multirow{3}{*}{$\begin{array}{l}\text { Information } \\
\text { timeliness } \\
\text { (IT) }\end{array}$} & IT1 & 0.863 & \multirow{3}{*}{0.849} & \multirow{3}{*}{0.908} & \multirow{3}{*}{0.767} \\
\hline & IT2 & 0.906 & & & \\
\hline & IT3 & 0.857 & & & \\
\hline \multirow{3}{*}{$\begin{array}{l}\text { Information } \\
\text { relevance (IR) }\end{array}$} & IR1 & 0.881 & \multirow{3}{*}{0.921} & \multirow{3}{*}{0.871} & \multirow{3}{*}{0.795} \\
\hline & IR2 & 0.902 & & & \\
\hline & IR3 & 0.891 & & & \\
\hline \multirow{2}{*}{$\begin{array}{c}\text { Information } \\
\text { sidedness (IS) }\end{array}$} & IS1 & 0.941 & \multirow{2}{*}{0.928} & \multirow{2}{*}{0.846} & \multirow{2}{*}{0.866} \\
\hline & IS2 & 0.921 & & & \\
\hline \multirow{3}{*}{$\begin{array}{l}\text { eWOM use } \\
\text { (USE) }\end{array}$} & USE1 & 0.888 & \multirow{3}{*}{0.909} & \multirow{3}{*}{0.850} & \multirow{3}{*}{$0.76 \mathrm{~S}$} \\
\hline & USE2 & 0.871 & & & \\
\hline & USE3 & 0.870 & & & \\
\hline
\end{tabular}

Table 5. Discriminant validity-correlations and square root of AVE

\begin{tabular}{l|llllll}
\hline Constructs & IA & IC & IT & IR & IS & USE \\
\hline IA & $\mathbf{0 . 8 7 5}$ & & & & & \\
IC & 0.750 & $\mathbf{0 . 8 8 7}$ & & & & \\
IT & 0.622 & 0.685 & $\mathbf{0 . 8 9 1}$ & & & \\
IR & 0.716 & 0.808 & 0.582 & $\mathbf{0 . 8 9 1}$ & & \\
IS & 0.533 & 0.563 & 0.656 & 0.612 & $\mathbf{0 . 9 3 1}$ & \\
USE & 0.470 & 0.490 & 0.346 & 0.556 & 0.354 & $\mathbf{0 . 8 7 7}$ \\
\hline
\end{tabular}

Note: Diagonal elements (in bold) are the square root of the average variance extracted (AVE). Off-diagonal elements are the correlations among constructs. For discriminant validity, diagonal values should be higher than off-diagonal ones.

Table 6. Discriminant validity-cross loadings

\begin{tabular}{l|l|l|l|l|l|l}
\hline Constructs & IA & IC & IT & IR & IS & USE \\
\hline IA1 & $\mathbf{0 . 8 3 6}$ & 0.509 & 0.522 & 0.545 & 0.458 & 0.438 \\
\hline IA2 & $\mathbf{0 . 8 8 1}$ & 0.557 & 0.537 & 0.485 & 0.442 & 0.387 \\
\hline IA3 & $\mathbf{0 . 9 0 8}$ & 0.605 & 0.567 & 0.549 & 0.496 & 0.411 \\
\hline IC1 & 0.514 & $\mathbf{0 . 8 9 6}$ & 0.590 & 0.662 & 0.501 & 0.387 \\
\hline IC2 & 0.511 & $\mathbf{0 . 9 1 5}$ & 0.600 & 0.540 & 0.512 & 0.489 \\
\hline IC3 & 0.470 & $\mathbf{0 . 8 4 8}$ & 0.631 & 0.543 & 0.483 & 0.427 \\
\hline IT1 & 0.488 & 0.564 & $\mathbf{0 . 8 6 3}$ & 0.634 & 0.489 & 0.418 \\
\hline IT2 & 0.571 & 0.615 & $\mathbf{0 . 9 0 5}$ & 0.548 & 0.595 & 0.452 \\
\hline IT3 & 0.573 & 0.623 & $\mathbf{0 . 8 5 8}$ & 0.626 & 0.640 & 0.363 \\
\hline IR1 & 0.589 & 0.582 & 0.512 & $\mathbf{0 . 8 8 1}$ & 0.540 & 0.492 \\
\hline IR2 & 0.572 & 0.557 & 0.556 & $\mathbf{0 . 9 0 3}$ & 0.581 & 0.494 \\
\hline IR3 & 0.560 & 0.526 & 0.623 & $\mathbf{0 . 8 9 2}$ & 0.526 & 0.503 \\
\hline IS1 & 0.494 & 0.557 & 0.577 & 0.595 & $\mathbf{0 . 9 4 0}$ & 0.356 \\
\hline IS2 & 0.498 & 0.485 & 0.527 & 0.548 & $\mathbf{0 . 9 2 1}$ & 0.311 \\
\hline USE1 & 0.406 & 0.431 & 0.412 & 0.507 & 0.291 & $\mathbf{0 . 8 8 8}$ \\
\hline USE2 & 0.355 & 0.414 & 0.386 & 0.464 & 0.293 & $\mathbf{0 . 8 7 1}$ \\
\hline USE3 & 0.477 & 0.453 & 0.441 & 0.490 & 0.361 & $\mathbf{0 . 8 7 0}$ \\
\hline
\end{tabular}

Note: Diagonal elements (in bold) are the factor loadings of each item for construct. Off-diagonal elements are the cross loadings of other items on the construct. For discriminant validity, diagonal values should be higher than off-diagonal values. 
Table 7. Discriminant validity-HTMT ratio

\begin{tabular}{l|llllll}
\hline Constructs & IA & IC & IT & IR & IS & USE \\
\hline IA & & & & & & \\
IC & 0.877 & & & & & \\
IT & 0.571 & 0.623 & & & & \\
IR & 0.833 & 0.830 & 0.537 & & & \\
IS & 0.629 & 0.655 & 0.622 & 0.716 & & \\
USE & 0.553 & 0.571 & 0.436 & 0.646 & 0.422 & \\
\hline
\end{tabular}

According to Podsakoff et al. (2003), if the data set is self-reported, the multiple sources such as consistency motif and social desirability would result in the potential problem of common method bias. In this research the data were collected based on the respondents' perceptions via self-reported questionnaire, common method bias might be a potential threat to the validity of this study. Following the suggestions on addressing common methods bias from Podsakoff et al. (2003), we have adopted procedural remedies in our survey design to minimize the potential effect of common method variance on the research findings. At the beginning of the online survey, the respondents have been informed that their answers to the questionnaire are anonymous, and they should select the choices which best describe their feelings based on their recent travel experience as there is no right or wrong answers. In addition, we have separated the variables included in the questionnaire into distinct sections when we designed the questionnaire. Furthermore, the common method bias was tested using the statistical analysis technique of Harmon's single-factor test (Podsakoff et al., 2003; Podsakoff and Organ, 1986). The analytic results show that the largest variance explained by an individual factor is $40.35 \%$. This means that none of the factors can explain the majority of the variance included in this study, indicating that common method bias is not an issue in this study (Podsakoff et al., 2003).

\section{Data analysis}

\subsection{Calibration}

In fsQCA, data calibration is necessary before analysis of the data commences. The calibration entails adapting all measurements with continuous scales into fuzzy sets with values ranging from 0 to 1 , to represent their degree of membership in a certain group - that is, the extent to which they are part of a group (Ragin, 2008). Specifically, a membership score of 1 indicates full membership in a set, and scores less than 1 but more than 0.5 indicate strong but partial membership in a set. Scores less than 0.5 but more than 0 indicate the membership is more "out" than "in" in a set, a score of 0.5 is the cross-over value indicating neither in nor out, and a membership score of 0 indicates fully out in a set.

Before data analysis, we converted all the raw data collected via the questionnaire into fuzzy-set values in the R software environment (Ragin, 2006). According to Ragin (2009), two main types of calibration methods can be used: direct and indirect. In this study, the calibration process involved using a direct method of data calibration with three qualitative breakpoints of the fuzzy sets, which identifies values from the range of the variables that correspond to full membership, the most ambitious membership, and full non-membership. The calibration depends on the researcher's substantive and theoretical knowledge with the underlying variables (Liu et al., 2017). In the research of (Liu et al., 2017), they have used 0.4 as an intermediate membership value rather than 0.5. According to them, applying 0.4 as an intermediate membership value can specify a slightly lower membership value for lower values in the five-item scale. In other words, it indicates a higher standard for intermediate memberships. If they transform an intermediate membership value into 0.5 , it would mean that "a neutral opinion positively contributes to the evaluation of a configuration" (Liu et al., 2017, p.68). To avoid this, they used 0.4 as an intermediate membership value in their 
calibration. In our study, we used qualitative anchoring to establish a connection between a fuzzy membership function and the original data. For variables measured on a 7-point Likert scale, the two extreme items, 1 and 7, were calibrated with membership values of 0 and 1 . Based on our substantive knowledge that the points on Likert scale to assess the variables in this study are not equidistant (Busch, 1993), and also following the study of Liu et al. (2017), the middle point of a seven-point Likert scale in this study was transferred to 0.4 to avoid that "a neutral opinion positively contributes to the evaluation of a configuration", and the intermediate items were assigned in a sub-linear way, given values of $0.13,0.27,0.4,0.6$, and 0.8 , instead of the equidistant values of $0.16,0.33,0.5,0.67$, and 0.84 . This indicates that a higher respondent score on the Likert-scale is required for intermediate memberships, and reflects the general knowledge that the points on the Likert scale are not equidistant (Busch, 1993).

The transformation into membership values for gender, as a binary variable, was performed by assigning maleness a fuzzy-set value denoting low membership (0) and femaleness full membership (1). The items on the amount of social media use time measured the number of hours of social media use per week. The calibration of the items on social media use time to fuzzy membership value is based on the authors' knowledge of the construct. According to a report on social media use in China in 2016, when the data was collected, users' average daily time spent on social media is about 2.5 hours (199it, 2017). In other words, users spend about 17.5 hours on social media every week, which is in the time range of the measurement "11-20 hours per week" for social media use time in this study. Thus, we set "11-20 hours per week" as the intermediate membership value of 0.5. And we set "under 5 hours per week" to the value of 0 , "5 to 10 hours per week" to 0.05 , and "more than 20 hours per week" to 1. Only those who have used social media more than 11 hours per week will contribute to the presence of "social media use time" in different configurations. Both variables - gender and social media use time - were calibrated after specification of the breakpoints for set membership.

\subsection{Qualitative comparative analysis}

After the data-calibration stage, an algorithm was applied to identify the configurations via use of the software fsQCA, v. 3.0. In the data analysis, we performed calculations in line with the assumption that the presence of information accuracy, information completeness, information relevance, information timeliness, and information sidedness is associated with the presence of the outcome of interest: eWOM use. Both gender and amount of social media use time, whether the values are high or low, should show some relationship to the presence of eWOM use.

The fsQCA algorithm produced a truth table consisting of $2^{7}$ rows of distinct combinations of attributes after calibration, since seven causal conditions were considered in our analysis. For every combination, the minimum membership value, denoting the degree to which every case supports the specific combination in question, was calculated, with the software using a threshold of 0.5 to identify those combinations acceptably supported by the cases. The last step was to sort the information in the truth table in accordance with frequency and consistency to reduce the number of rows in the table (Ragin, 2008), where the frequency is the minimum number of cases necessary for a solution to be considered (Fiss, 2011) and consistency describes "the degree to which cases correspond to the set-theoretic relationships expressed in a solution" (Fiss, 2011: 402).

According to Ragin (2009), the threshold value of frequency depends on the sample size; a cutoff point of 1 is appropriate for small- and medium-sized samples, and it should be set higher for largescale samples (e.g., over 150 cases). In our research, the frequency cutoff is set as 3 (Fiss, 2011), and the lowest acceptable consistency for solutions is 0.97 (Ragin, 2009).

An analysis of necessity was first performed to test if any causal condition is a necessary condition for the presence of eWOM use behavior. From a set theory perspective, necessity means a condition 
is a superset of the outcome(Ragin, 2006). For a condition to be necessary, its consistency should exceed the threshold of 0.9 (Schneider and Wagemann, 2010). The dedicated function of necessity analysis in fsQCA software is used to examine the necessity as well as the consistency and coverage scores for every causal condition and their negation. Regarding both presence and absence (i.e., negation) of a causal condition, none of the causal conditions in this study is the necessary condition for the eWOM use behavior.

Table 8 depicts the configurations of the antecedent conditions found to be associated with high membership values for the outcome condition, eWOM use in supporting travel-related decisionmaking. Each combination is a solution that explains the eWOM use outcome. In the table, the presence of a condition is denoted by a black circle $(\bullet)$, and a crossed-out circle indicates its absence $(\otimes)$. Empty cells indicate a "doesn't matter" situation, meaning that the given causal condition may be absent or present. As the overall solution coverage of 0.795 presented in Table 8 suggests, the two solutions account for a substantial proportion of the cases in which eWOM use behavior is highly probable (Woodside, 2013). Both the overall consistency and the consistency values for every configuration exceed the recommended threshold (0.75), which indicates that all the configurations are sufficient for yielding the outcome of interest (Fiss, 2011). In addition, fsQCA computes the empirical relevance of every solution in terms of the raw and unique coverage. The former is "the amount of the outcome that is explained by a certain alternative solution," and unique coverage is "the amount of the outcome that is exclusively explained by a certain alternative solution" (Pappas et al., 2017).

According to Fiss (2011), the configurations can be further classified into first- and second-order solutions on the basis of the equifinality of the different core conditions exhibited. In this study, we identified two first-order equifinality of Solution 1 and Solution 2, along with a second-order within-type equifinality for Solution 3 (3a 3d), as shown in Table 8.

Table 8. Intermediate solutions with the fsQCA method

\begin{tabular}{|c|c|c|c|c|c|c|c|c|c|c|c|c|}
\hline \multirow[b]{2}{*}{ Solutions } & \multirow[b]{2}{*}{ IA } & \multicolumn{6}{|c|}{ Causal conditions } & \multicolumn{5}{|l|}{ Metrics } \\
\hline & & IC & IT $\mathrm{I}$ & IR & IS & $\begin{array}{l}\text { Social media } \\
\text { use time }\end{array}$ & Gender & $\begin{array}{l}\text { Raw } \\
\text { coverage }\end{array}$ & $\begin{array}{l}\text { Unique } \\
\text { coverage }\end{array}$ & Consistency & $\begin{array}{l}\text { Solution } \\
\text { coverage }\end{array}$ & \begin{tabular}{|l|} 
Solution \\
consistency
\end{tabular} \\
\hline 1 & $\bullet$ & & & & & $\otimes$ & $\bullet$ & 0.368 & 0.017 & 0.960 & \multirow{6}{*}{0.795} & \multirow{6}{*}{0.954} \\
\hline 2 & & - & & $\bullet$ & & $\otimes$ & $\bullet$ & 0.359 & 0.015 & 0.967 & & \\
\hline $3 a$ & $\bullet$ & $\bullet$ & $\cdot$ & $\bullet$ & 0 & & & 0.709 & 0.062 & 0.979 & & \\
\hline $3 b$ & $\bullet$ & $\bullet$ & & $\bullet$ & 0 & $\otimes$ & & 0.554 & 0.003 & 0.977 & & \\
\hline $3 \mathrm{c}$ & $\bullet$ & & - & $\bullet$ & $\bullet$ & & $\bullet$ & 0.431 & 0.004 & 0.979 & & \\
\hline $3 d$ & & & $\bullet$ & & $\bullet$ & $\otimes$ & $\otimes$ & 0.243 & 0.016 & 0.941 & & \\
\hline
\end{tabular}

To illustrate the relationships between the outcome of interest ("eWOM use") and the configurations identified in fsQCA, the fuzzy membership values for an observation were calculated and illustrated in Figure 1. As depicted in the plots in Figure 1, most of the points are above the diagonal line, which indicates that the fuzzy membership value in the eWOM use intention is higher than the membership in the combination. Therefore, the sufficiency of a causal combination is supported. Additionally, the figures indicate an asymmetric relationship between the eWOM use and the antecedent combination, which supports the appropriateness of the fsQCA approach. 
Figure 1. Fuzzy XY plots for Solutions 1, 2, and 3a-d

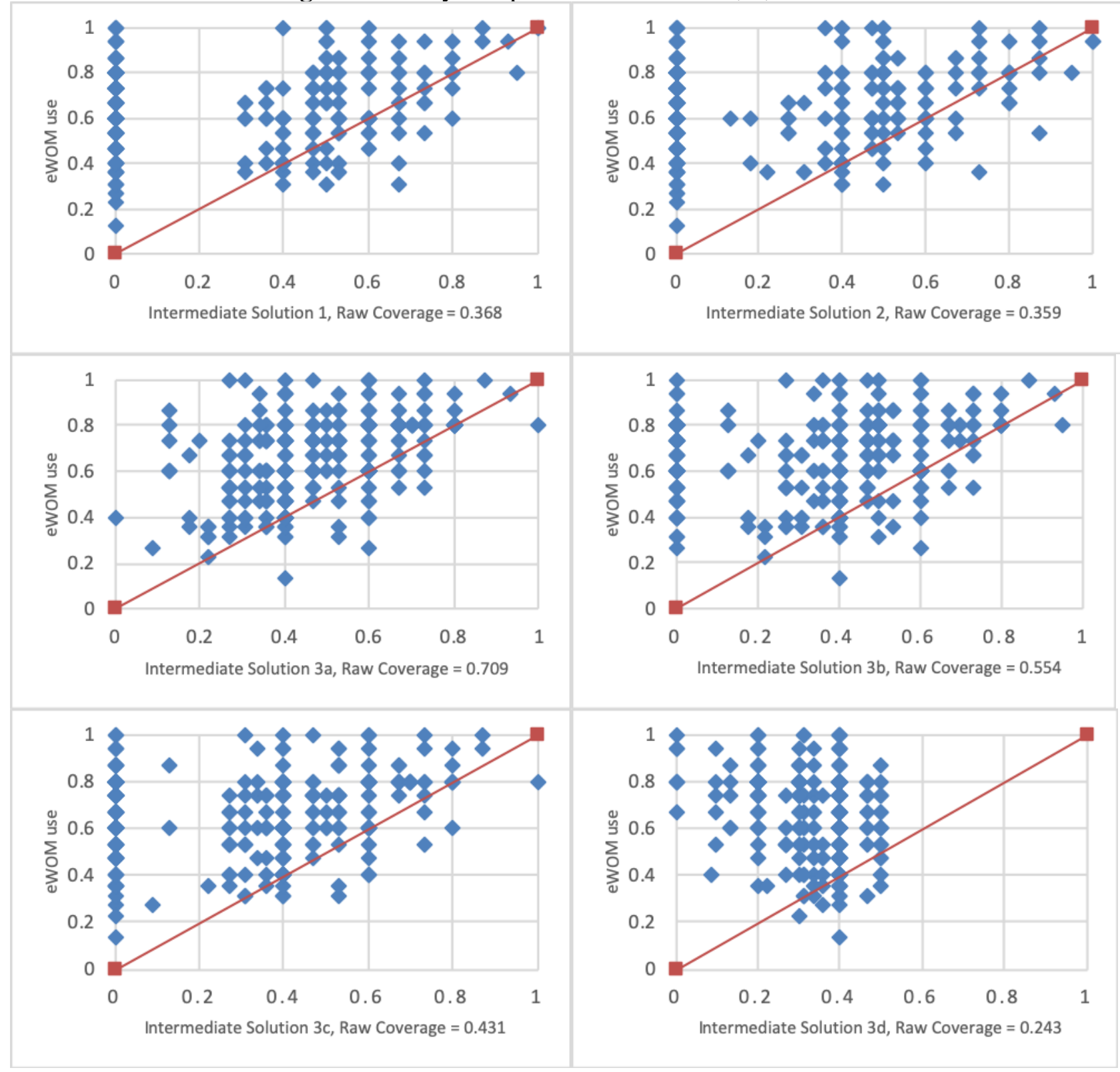

\section{Discussion and conclusions}

\subsection{Discussion}

The fsQCA results reveal three major configurations of causal conditions that underlie consumers' eWOM use. As shown in Table 8, each of the three configurations displays a distinctive pattern of core, peripheral, and neutral conditions.

Two configurations (Solutions 1 and 2) are identified for female consumers who use social media less, such as less than 10 hours per week. Solution 1 holds that eWOM accuracy is a core condition for female consumers who use social media less than 10 hours per week. This solution reveals that for female consumers, eWOM accuracy, in combination with less social media use time (such as less than 10 hours per week), are sufficient for females' eWOM use despite the absence of eWOM completeness, sidedness, relevance, and timeliness. In the literature, eWOM accuracy has been shown to be an important factor leading to consumers' eWOM use (Cheung and Thadani, 2012; Filieri and McLeay, 
2014). Solution 1 indicates that information accuracy is not sufficient in driving eWOM use; eWOM accuracy should be present together with the other peripheral factors, such as gender and social media use time. If female consumers use social media less than 10 hours per week and perceive the eWOM to be accurate, they will use the eWOM to support their travel decisions. Otherwise, they will not use the eWOM even though eWOM accuracy has been suggested to be important in supporting consumers' travel decisions (Filieri et al., 2015).

Conversely, with Solution 2 we found eWOM completeness to be another core predictive element for females who use social media less than 10 hours per week. For female consumers, eWOM completeness in combination with eWOM relevance as well as less social media use time (such as less than 10 hours per week) is sufficient for their eWOM use irrespective of the presence of eWOM accuracy, sidedness, and timeliness. In the extant literature, past studies have illustrated that eWOM completeness is positively related to user satisfaction with information quality (Xu et al., 2013), and an eWOM with more complete information is more useful and leads to consumers' use of the eWOM (Cheung et al., 2008). Solution 2 indicates that eWOM completeness is not sufficient in driving eWOM use. eWOM completeness should be combined with other factors, such as gender, social media use time, and eWOM relevance, to explain eWOM use. In other words, eWOM completeness will be sufficient for female consumers' eWOM use only if they use social media less (such as less than 10 hours per week) and also perceive the eWOM to be relevant to their needs.

As shown in Solution 3, eWOM sidedness is the core condition for eWOM use, indicating that a balanced review is persuasive and important for a consumer to evaluate the overall quality of a product/service and support their purchasing decisions. Scholars in marketing have shown that a twosided review is more influential on belief change as it induces fewer counterarguments, thus leading to less source derogation (Craciun and Moore, 2019). As illustrated in Table 8, Solution 3 covers four configurations of causal conditions: Solutions $3 \mathrm{a}, 3 \mathrm{~b}, 3 \mathrm{c}$, and $3 \mathrm{~d}$. These solutions can be regarded as together providing a detailed characterization of the main features of four key subgroups of eWOM users under the umbrella of Solution 3. The solutions indicate the importance of eWOM sidedness in driving eWOM use.

Specifically, Solution 3a shows that eWOM sidedness is a sufficient condition for eWOM use consumers if consumers also have positive perceptions about the eWOM accuracy, completeness, relevance, and timeliness, regardless of their social media use time and gender. For female consumers, the presence of eWOM sidedness is a sufficient condition for their eWOM use if they also perceive the eWOM to be accurate, relevant, and timely (Solution 3c). For male consumers, eWOM sidedness is also a sufficient condition for their eWOM use only if they use social media less (such as less than 10 hours per week) and also possess positive perceptions about the timeliness of the eWOM (Solution 3d). Previous research has also demonstrated that the determinants of eWOM use behavior vary between males and females (Mishra et al., 2018). Solution 3b describes that for consumers who use social media less (such as less than 10 hours per week), regardless of their gender, the presence of eWOM sidedness is a sufficient condition for eWOM use only if the consumers perceive the eWOM information to be accurate, complete, and relevant.

As shown in Table 8, Solution 1 covers $36.8 \%$ of the membership values, whereas Solution 2 covers $35.9 \%$ of the membership values. Solution 3 covers four configurations of causal conditions, covering the membership values from $24.3 \%$ to $70.9 \%$. The solutions identified in this study are the sufficient configurations of causal conditions for eWOM use among consumers. The raw coverage of Solution $3 \mathrm{a}$ is 0.709 , the highest among all the configurations, indicating that Solution $3 \mathrm{a}$ is the most prevalent configuration driving consumers' eWOM use. 


\subsection{Theoretical implications}

By taking an fsQCA approach to predict eWOM use, this research carries some theoretical implications in the field of eWOM. First, this research contributes to the eWOM literature by providing the configurations of causal conditions driving eWOM use from a configuration perspective. This study shifts the emphasis from a symmetric paradigm to an asymmetric perspective for data analysis focused on eWOM use, which enriches the extant literature on eWOM use based on the traditional statistical regression analysis, such as SEM, which concentrates on the net impact of individual factor on eWOM use. With its different methodological approach, the work provides an in-depth understanding of the interplay among multiple variables that function as predictors of eWOM use, thereby complementing the knowledge yielded by traditional regression analysis, which has highlighted the net effect of each individual predictor. The research findings also indicate that fsQCA approach can be applied in research to explain eWOM use as an alternative research method to the traditional statistical regression analysis.

Second, several configurations among the given set of variables were identified to predict the relevant outcome, eWOM use. The configurations uncover the asymmetric relations between the predictors and eWOM use, which enriches the current literature on eWOM use focusing on the symmetric relationships between the predictors and eWOM use. This research into identifying multiple combinations (configurations) in eWOM use via fsQCA should benefit theory-building related to eWOM use and provides knowledge about the role of eWOM information quality (such as eWOM accuracy, completeness, sidedness, relevance, and timeliness) and consumer-specific characteristics (social media use time and gender) in predicting eWOM use.

Third, this research also contributes to the understanding of the relevant importance of different dimensions of eWOM information quality and how their importance is associated with consumers' gender and social media use by identifying the core and peripheral factors driving eWOM use from a configuration standpoint. The findings provide further evidence that eWOM use behavior varies among females and males as well as among users with different social media use experience (such as social media use time), and the determinants for their eWOM use are also different (Abubakar et al., 2017).

\subsection{Practical implications}

At a practical level, the study provides useful insights for eWOM practitioners striving to harness the power of eWOM to support consumers' travel-related decision-making. Among the key findings is that factors related to eWOM information quality and traits of the consumers, when considered in combination, can predict eWOM use behavior in particular sets of conditions and facilitate consumers turning to eWOM to support their purchase-related decision-making.

In this study, multiple configurations of casual conditions facilitating eWOM use have been identified based on eWOM information quality and consumer characteristics. The study findings indicate that a single dimension of eWOM information quality cannot guarantee eWOM use among different consumer segments, and combining the different dimensions of eWOM information quality with other factors should be taken into consideration in eWOM use among consumers. Thus, eWOM practitioners, such as travel-related eWOM platforms and other travel organizations involved in eWOM, should take different strategies to facilitate consumers' use of eWOM on the travel-related eWOM platforms or eWOM about specific travel service organizations, such as hotels, travel destinations, etc.

First, in this study, eWOM sidedness was found to be a core condition for eWOM use among different online tourism consumer groups with different peripheral conditions. The research finding indicates that two-sided eWOM, such as eWOM with both positive and negative review contents, on 
travel-related eWOM platforms can attract other online tourism consumers to use the eWOM to support their travel decisions. This finding also provides practical suggestion to travel service providers that they should not only highlight the role of positive eWOM in marketing their business, but also consider about the importance of negative eWOM related to their services. They should accept the sidedness of online reviews on their services since eWOM sidedness is a core and sufficient condition for eWOM use among different online tourism consumer groups. In addition, travel service providers should also understand the importance of aforementioned peripheral conditions which should be taken into consideration to trigger the main effect of eWOM sidedness. For instance, eWOM practitioners can take some strategies to encourage timely online reviews via sending reminds for review generating after consumers' trips. These strategies will facilitate eWOM use for male consumers who use social media less (Solution 3d). The above strategies will also facilitate both female and male consumers regardless of their social media use time if the eWOM are accurate, complete, relevant (Solution 3b) and timely (3a), as well as for female users if the eWOM are also accurate, relevant and timely regardless of their social media use time (Solution $3 \mathrm{c}$ ).

Second, practitioners should make strategies in encouraging consumers to write online reviews covering different dimensions of eWOM information quality in order to enhance eWOM use. For instance, eWOM practitioners should encourage consumers to write online reviews with more specific details related to a travel service/product (information completeness and relevance), to provide more accurate information of a travel product/service in online reviews (information accuracy), to provide both positive and negative aspects of a travel product/service in online reviews (sidedness) shortly after their trips (timeliness). The strategies will attract female consumers with less social media use time to use the eWOM to support their travel decisions if the eWOM are either accuracy (Solution 1), or complete in combination with relevance (Solution 2). In addition, these strategies will also help to trigger the core effect of eWOM sidedness, accuracy and completeness in combinations with the other dimensions of eWOM information quality (peripheral conditions).

Third, eWOM accuracy, completeness and sidedness were identified as the core elements for eWOM in the configurations of the casual conditions for eWOM use. The research findings highlight the importance of eWOM accuracy, completeness and sidedness in driving eWOM use. However, eWOM accuracy, completeness and sidedness will drive eWOM use only if combined with eWOM relevance, timeliness, consumers' social media use time and gender. Thus, eWOM practitioners should consider both the core and the peripheral conditions triggering eWOM use among different consumer segments. They should take strategies to encourage consumers to write eWOM with a combination of the five different dimensions of eWOM information quality (information accuracy, information completeness, information sidedness, information relevance, and information timeliness), but not only highlight the eWOM accuracy, completeness and sidedness, in order to facilitate different user groups, such as female and male consumers and consumers with different social media use experience.

\subsection{Limitations and future research}

Several limitations should be noted. First, users' perceptions of eWOM quality were measured at a general level, without a focus on a specific product class, such as hotels, destinations, or restaurants. Work centered on certain types of eWOM could provide more specific guidelines for scholars and practitioners alike. Second, only five dimensions of eWOM information quality and two consumer traits were investigated in the exploration of configurations; further research could address more factors related to eWOM content (such as information consistency, review length, and understandability) and consumers (such as age and travel style), and also take into consideration the characteristics of eWOM platforms (the information channel). In addition, the source of eWOM, the reviewers, should be taken into consideration in future research. 


\section{References}

199it. (2017), “年轻人有 $1 / 3$ 的网络时间都用在了社交媒体上”, available at: http://www.199it.com/archives/607975.html (accessed 27 November 2019).

Abubakar, A.M., Ilkan, M., Meshall Al-Tal, R. and Eluwole, K.K. (2017), "eWOM, revisit intention, destination trust and gender", Journal of Hospitality and Tourism Management, Vol. 31, pp. $220-227$.

Ahmad, S.N. and Laroche, M. (2015), "How do expressed emotions affect the helpfulness of a product review? Evidence from reviews using latent semantic analysis", International Journal of Electronic Commerce, Vol. 20 No. 1, pp. 76-111.

Bacon, E., Williams, M.D. and Davies, G.H. (2019), "Recipes for success: Conditions for knowledge transfer across open innovation ecosystems", International Journal of Information Management, Vol. 49, pp. 377-387.

Baek, H., Ahn, J. and Choi, Y. (2012), “Helpfulness of online consumer reviews: Readers' objectives and review cues", International Journal of Electronic Commerce, Vol. 17 No. 2, pp. 99-126.

Bagozzi, R.P., Fornell, C. and Larcker, D.F. (1981), "Evaluating structural equation models with unobservable variables and measurement error", Journal of Marketing Research, Vol. 18 No. 1, pp. 39-50.

Beynon, M.J., Jones, P. and Pickernell, D. (2019), “The role of entrepreneurship, innovation, and urbanity-diversity on growth, unemployment, and income: US state-level evidence and an fsQCA elucidation", Journal of Business Research, Vol. 101, pp. 675-687.

Bronner, F. and De Hoog, R. (2011), "Vacationers and eWOM: Who posts, and why, where, and what?", Journal of Travel Research, Vol. 50 No. 1, pp. 15-26.

Busch, M. (1993), "Using Likert Scales in L2 Research A Researcher Comments”, TESOL Quarterly, Vol. 27 No. 4, pp. 733-736.

Cheung, C.M.-Y., Sia, C.-L. and Kuan, K.K.Y. (2012), "Is this review believable? A study of factors affecting the credibility of online consumer reviews from an ELM perspective", Journal of the Association for Information Systems, Vol. 13 No. 8, pp. 618-635.

Cheung, C.M.K., Lee, M.K. and Rabjohn, N. (2008), "The impact of electronic word-of-mouth: The adoption of online opinions in online customer communities", Internet Research, Vol. 18 No. 3 , pp. 229-247.

Cheung, C.M.K. and Thadani, D.R. (2012), "The impact of electronic word-of-mouth communication: A literature analysis and integrative model", Decision Support Systems, Vol. 54 No. 1, pp. 461470.

Cooper, B. and Glaesser, J. (2011), "Using case-based approaches to analyse large datasets: a comparison of Ragin's fsQCA and fuzzy cluster analysis", International Journal of Social Research Methodology, Vol. 14 No. 1, pp. 31-48.

Craciun, G. and Moore, K. (2019), "Credibility of negative online product reviews: Reviewer gender, reputation and emotion effects", Computers in Human Behavior, Vol. 97, pp. 104-115.

Dickinger, A. (2011), "The trustworthiness of online channels for experience-and goal-directed search tasks", Journal of Travel Research, Vol. 50 No. 4, pp. 378-391. 
Filieri, R. (2016), "What makes an online consumer review trustworthy?", Annals of Tourism Research, Vol. 58, pp. 46-64.

Filieri, R., Alguezaui, S. and McLeay, F. (2015), "Why do travelers trust TripAdvisor? Antecedents of trust towards consumer-generated media and its influence on recommendation adoption and word of mouth", Tourism Management, Vol. 51, pp. 174-185.

Filieri, R. and McLeay, F. (2014), "E-WOM and Accommodation: An Analysis of the Factors That Influence Travelers' Adoption of Information from Online Reviews", Journal of Travel Research, Vol. 53 No. 1, pp. 44-57.

Fiss, P.C. (2011), "Building better causal theories:A fuzzy set approach to typologies in organizational research", The Academy of Management Journal, Vol. 54 No. 2, pp. 393-420.

Hair, J.F., Hult, G.T.M., Ringle, C.M. and Sarstedt, M. (2013), A Primer on Partial Least Squares Structural Equation Modeling (PLS-SEM), SAGE Publications Inc.

Henseler, J., Ringle, C.M. and Sarstedt, M. (2015), "A new criterion for assessing discriminant validity in variance-based structural equation modeling", Journal of the Academy of Marketing Science, Vol. 43 No. 1, pp. 115-135.

Hu, Y.-H., Chen, K. and Lee, P.-J. (2016), “The effect of user-controllable filters on the prediction of online hotel reviews", Information \& Management, Vol. 54 No. 6, pp. 728-744.

Hussain, S., Guangju, W., Jafar, R.M.S., Ilyas, Z., Mustafa, G. and Jianzhou, Y. (2018), “Consumers' online information adoption behavior: Motives and antecedents of electronic word of mouth communications", Computers in Human Behavior, Vol. 80, pp. 22-32.

Kent, R.A. (2005), "Cases as configurations: Using combinatorial and fuzzy logic to analyse marketing data”, International Journal of Market Research, Vol. 47 No. 2, pp. 205-228.

Kim, E.E.K., Mattila, A.S. and Baloglu, S. (2011), "Effects of gender and expertise on consumers' motivation to read online hotel reviews", Cornell Hospitality Quarterly, Vol. 52 No. 4, pp. 399406.

Kim, K., Cheong, Y. and Kim, H. (2017), "User-generated product reviews on the internet: the drivers and outcomes of the perceived usefulness of product reviews", International Journal of Advertising, Vol. 36 No. 2, pp. 227-245.

Kourouthanassis, P.E., Mikalef, P., Pappas, I.O. and Kostagiolas, P. (2017), “Explaining travellers online information satisfaction: A complexity theory approach on information needs, barriers, sources and personal characteristics", Information \& Management, Vol. 54 No. 6, pp. 814-824.

Kraus, S., Ribeiro-Soriano, D. and Schussler, M. (2018), "Fuzzy-set qualitative comparative analysis (fsQCA) in entrepreneurship and innovation research - the rise of a method", International Entrepreneurship and Management Journal, Vol. 14 No. 1, pp. 15-33.

Li, H., Li, L., Gan, C., Liu, Y., Tan, C.-W.W. and Deng, Z. (2018), "Disentangling the factors driving users' continuance intention towards social media: A configurational perspective", Computers in Human Behavior, Vol. 85, pp. 175-182.

Liu, Y., Mezei, J., Kostakos, V. and Li, H. (2017), “Applying configurational analysis to IS behavioural research: a methodological alternative for modelling combinatorial complexities", Information Systems Journal, Vol. 27 No. 1, pp. 59-89. 
Luo, Q.J. and Zhong, D.X. (2015), "Using social network analysis to explain communication characteristics of travel-related electronic word-of-mouth on social networking sites", Tourism Management, Vol. 46, pp. 274-282.

Matook, S., Brown, S.A. and Rolf, J. (2015), "Forming an intention to act on recommendations given via online social networks", European Journal of Information Systems, Vol. 24 No. 1, pp. 76-92.

Mendel, J.M. and Korjani, M.M. (2012), “Charles Ragin's fuzzy set qualitative comparative analysis (fsQCA) used for linguistic summarizations", Information Sciences, Vol. 202, pp. 1-23.

Mikalef, P. and Pateli, A. (2017), "Information technology-enabled dynamic capabilities and their indirect effect on competitive performance: Findings from PLS-SEM and fsQCA", Journal of Business Research, Vol. 70, pp. 1-16.

Mishra, A., Maheswarappa, S.S., Maity, M. and Samu, S. (2018), “Adolescent's eWOM intentions: An investigation into the roles of peers, the Internet and gender", Journal of Business Research, Vol. 86, pp. 394-405.

Mudambi, S.M. and Schuff, D. (2010), "Research note: What makes a helpful online review? A study of customer reviews on Amazon. com”, MIS Quarterly, Vol. 34 No. 1, pp. 185-200.

Ortiz de Guinea, A. and Raymond, L. (2020), "Enabling innovation in the face of uncertainty through IT ambidexterity: A fuzzy set qualitative comparative analysis of industrial service SMEs", International Journal of Information Management, Vol. 50, pp. 244-260.

Pappas, I., Mikalef, P. and Giannakos, M. (2016), "User Experience in Personalized E-Commerce: A Configurational Approach", Twenty-Second Americas Conference on Information Systems (AMCIS), San Diego, pp. 1-10.

Pappas, I.O., Giannakos, M.N. and Sampson, D.G. (2017), "Fuzzy set analysis as a means to understand users of 21 st-century learning systems: The case of mobile learning and reflections on learning analytics research", Computers in Human Behavior, Vol. 92, pp. 1-14.

Pappas, I.O., Mikalef, P., Giannakos, M.N. and Kourouthanassis, P.E. (2019), "Explaining user experience in mobile gaming applications: an fsQCA approach", Internet Research, Vol. 29 No. 2, pp. 293-314.

Pappas, N. (2018), "Hotel decision-making during multiple crises: A chaordic perspective", Tourism Management, Vol. 68, pp. 450-464.

Pappas, N. (2019), "The complexity of consumer experience formulation in the sharing economy”, International Journal of Hospitality Management, Vol. 77, pp. 415-424.

Park, D.H. and Kim, S. (2008), "The effects of consumer knowledge on message processing of electronic word-of-mouth via online consumer reviews", Electronic Commerce Research and Applications, Vol. 7 No. 4, pp. 399-410.

Park, S. and Nicolau, J.L. (2015), “Asymmetric effects of online consumer reviews", Annals of Tourism Research, Vol. 50, pp. 67-83.

Pérez Durán, I. and Rodríguez Menés, J. (2017), "Explaining accountability for public policies: an fsQCA analysis of health policy in Spain”, European Political Science Review, Vol. 9 No. 3, pp. 329-350. 
Podsakoff, P.M., MacKenzie, S.B., Lee, J.-Y. and Podsakoff, N.P. (2003), “Common method biases in behavioral research: a critical review of the literature and recommended remedies", Journal of Applied Psychology, Vol. 88 No. 5, p. 879.

Podsakoff, P.M. and Organ, D.W. (1986), "Self-reports in organizational research: Problems and prospects", Journal of Management, Vol. 12 No. 4, pp. 531-544.

Ragin, C.C. (2000), Fuzzy-Set Social Science, University of Chicago Press.

Ragin, C.C. (2006), "Set Relations in Social Research: Evaluating Their Consistency and Coverage", available at: http://www.u.arizona.edu/ cragin/fsQCA/download/Con_cov.pdf (accessed 20 January 2019).

Ragin, C.C. (2008), "User's guide to Fuzzy-Set/Qualitative Comparative Analysis", available at: http://www.u.arizona.edu/ cragin/fsQCA/download/fsQCAManual.pdf (accessed 16 December 2018).

Ragin, C.C. (2009), Redesigning Social Inquiry: Fuzzy Sets and Beyond, University of Chicago Press.

Ragin, C.C. (2014), The Comparative Method: Moving beyond Qualitative and Quantitative Strategies, University of California Press.

Reichelt, J., Sievert, J. and Jacob, F. (2014), "How credibility affects eWOM reading: The influences of expertise, trustworthiness, and similarity on utilitarian and social functions", Journal of Marketing Communications, Vol. 20 No. 1-2, pp. 65-81.

Schneider, C.Q. and Wagemann, C. (2010), "Standards of good practice in qualitative comparative analysis (QCA) and fuzzy-sets”, Comparative Sociology, Vol. 9 No. 3, pp. 397-418.

Serra Cantallops, A. and Salvi, F. (2014), "New consumer behavior: A review of research on eWOM and hotels", International Journal of Hospitality Management, Vol. 36, pp. 41-51.

Sparks, B.A., Perkins, H.E. and Buckley, R. (2013), “Online travel reviews as persuasive communication: The effects of content type, source, and certification logos on consumer behavior", Tourism Management, Vol. 39, pp. 1-9.

Sussman, S.W. and Siegal, W.S. (2003), "Informational Influence in Organizations: An Integrated Approach to Knowledge Adoption”, Information Systems Research, Vol. 14 No. 1, pp. 47-65.

Tho, N.D. (2018), "A Configurational Role of Human Capital Resources in the Quality of Work Life of Marketers: FsQCA and SEM Findings from Vietnam", Applied Research in Quality of Life, Vol. 13 No. 2, pp. 461-478.

To, C.K.M., Au, J.S.C. and Kan, C.W. (2019), "Uncovering business model innovation contexts: A comparative analysis by fsQCA methods", Journal of Business Research, Vol. 101, pp. 783-796.

Tour.youth.cn. (2019), “”她经济”不容忽视 女性渐成旅游消费市场主导者”, available at: http://tour.youth.cn/xw/201903/t20190308_11890221.htm (accessed 25 November 2019).

Travel Daily. (2018), “中国旅游研究院+携程：2018中国在线旅游发展大数据指数报告”, available at: https://www.traveldaily.cn/article/124763 (accessed 10 August 2019). 
Vizcaino-Gonzalez, M., Pineiro-Chousa, J. and Sainz-Gonzalez, J. (2017), "Selecting explanatory factors of voting decisions by means of fsQCA and ANN", Quality \& Quantity, Vol. 51 No. 5, pp. 2049-2061.

Woodside, A.G. (2013), "Moving beyond multiple regression analysis to algorithms: Calling for adoption of a paradigm shift from symmetric to asymmetric thinking in data analysis and crafting theory”, Journal of Business Research, Vol. 66 No. 4, pp. 463-472.

Xu, J.D., Benbasat, I. and Cenfetelli, R.T. (2013), "Integrating service quality with system and information quality: an empirical test in the e-service context", MIS Quarterly, Vol. 37 No. 3, pp. 777-794.

$\mathrm{Xu}, \mathrm{Q}$. (2014), "Should I trust him? The effects of reviewer profile characteristics on eWOM credibility", Computers in Human Behavior, Vol. 33, pp. 136-144.

Zhang, K.Z.K., Zhao, S.J., Cheung, C.M.K. and Lee, M.K.O. (2014), "Examining the influence of online reviews on consumers' decision-making: A heuristic-systematic model", Decision Support Systems, Vol. 67, pp. 78-89. 